Technological University Dublin

DƯBLIN

ARROW@TU Dublin

Articles

Dublin School of Architecture

2015-06-01

\title{
Work-related Stress: Survey of Academic Staff in the Institutes of Technology Sector
}

Aidan Kenny

Technological University Dublin, aidan.kenny@tudublin.ie

Follow this and additional works at: https://arrow.tudublin.ie/bescharcart

Part of the Higher Education Commons, Labor and Employment Law Commons, and the Other

Education Commons

\section{Recommended Citation}

Kenny A. (2015) Work-related Stress: Survey of academic staff in the Institutes of Technology Sector, DIT Level3, Issue 13, June 2015

This Article is brought to you for free and open access by the Dublin School of Architecture at ARROW@TU Dublin. It has been accepted for inclusion in Articles by an authorized administrator of ARROW@TU Dublin. For more information, please contact arrow.admin@tudublin.ie, aisling.coyne@tudublin.ie,gerard.connolly@tudublin.ie.

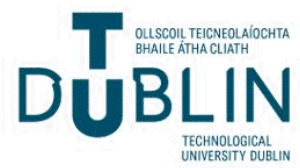




\title{
Work-related Stress: Survey of academic staff in the Institutes of Technology Sector
}

\author{
Author: Dr Aidan Kenny \\ Dublin Institute of Technology, currently on secondment to the Teachers' Union of Ireland
}

\begin{abstract}
This article presents findings from a survey of professional workers in the institutes of technology sector in Ireland regarding work-related stress. The research instrument was based on a work-related stress questionnaire developed by the UK Health and Safety Executive, augmented with a specific subset of questions relevant to the Irish higher education sector. The questionnaire format was modified to enable online delivery. It was distributed to a sample population in 2014 with a response rate over $30 \%(n=1,131)$. The research provides baseline data on work-related stress levels experienced by workers in this sector. The results associate increased levels of risk of work-related stress in circumstances of poor consultation, lack of engagement with staff, excessive workload, demanding task with unrealistic deadlines and lack of support provided by management. Low risk levels were associated with peer support and relationships. Good social relations between workers seem to assist in the alleviation of the risk. The results support established research into work-related stress which claims that developing supportive working environments and work cultures can greatly assist in the reduction of risk levels.
\end{abstract}

Key words: higher education; research; Ireland; baseline data; professional trade union

\section{Introduction}

The World Health Organisation has indicated that work-related stress can have an adverse impact on workers' physical and psychological health, including their well-being. The European Agency for Safety and Health at Work (2009) research suggests that over $22 \%$ of workers in EU countries have reported experiencing work-related stress, at an estimated cost to the economy of over $€ 20,000$ million per annum. In the UK recent research (2014) claims that $39 \%$ of work-related illness was due to work-related stress, depression and anxiety. The Central Statistics Office Quarterly Household Survey (2012) indicated 16,122 reported cases of work-related stress. Work-related stress is a significant labour force issue which can cause illness within the workforce, decrease economic productivity due to 
increased sick-leave absence, and contribute to the pressure on public finances arising for increased use of the public health systems.

The research described in this article was commissioned by the Teachers' Union of Ireland (TUI) to provide baseline data on work-related stress levels experienced by its members who work in the higher education sector. The sample population was confined to the fourteen institutes of technology. According to the Higher Education Authority (HEA) first quarter returns for 2015 there were 4,390.85 whole-time equivalent (WTE) academic staff and 1,002.32 WTE research/project ${ }^{1}$ staff in that sector. The research focused on the academic staff who were members of the Union at the time. The research used a recognised standardised questionnaire augmented with specific localising questions to measure levels of work-related stress within a work environment. The research approach was an 'inductive research strategy' (Blaikie 2007, p9) consisting of gathering data, analysing data and the application of inductive logic to ascertain generalisations. The initial focus of the research is 'descriptive' (Robson 1993, p127), establishing baseline characteristics of the sample population by means of a survey. The method involved administration of an online survey to the sample population. The survey contained both the standardised questionnaire and a separate subset of questions with items of specific interests to the academic staff in the Institutes. The analysis provides an account of the whole sector and a comparison between workplaces/discrete Institutes.

The article is structured into the following components: preliminary literature review of work-related stress; the questionnaire instrument and methods applied; considerations of the response rate; presentation of the findings from the standardised instrument and the third level subset survey.

\section{Work-Related Stress}

According to the Labour Force Survey $(2015)$ in Britain $39 \%(n=487,000)$ of all work-related illness reported in 2013-2014 was categorised as 'work-related stress, depression or anxiety'. In the same period the total number of working days lost to work-related stress, anxiety or depression was 11.3 million. The occupations that are identified with the

\footnotetext{
${ }^{1}$ Research and project staff were not part of the sample population. The union only got negotiation rights for the grade of researchers in 2014 and is actively recruiting.
} 
highest levels of work-related stress, depression or anxiety are health care, social work, education and public administration. The 2012-2013 THOR-GP (UK) report identified the three key work issues leading to 'work-related stress, depression and anxiety' as workloads, changes at work, and interpersonal relationships. Research by the European Agency for Safety and Health at Work (EASHW) Pan-European Opinion Poll on Occupational Safety and Health (2013) which was based on $n=16,622$ interviews found the three major work-related stress factors identified; (1) Job recognition - Job insecurity $72 \%$, (2) Hours worked - Workloads 62\% and (3) Inappropriate behaviour - bullying 51\%. When the results are disaggregated for the Irish case study ( $n=546$ interviews) the three highest stress factors are (i) Job recognition - Job security 76\%, (ii) Hours worked - Workloads 73\% and (iii) inappropriate behaviour - bullying 70\%. The Central Statistics Office Quarterly Household Survey (CSO-QHS) suggests the scope of reported cases of work-related stress, depression and anxiety was $n=16,122$ in 2012 . Work-related stress, depression or anxiety account for significant losses of working time and cause substantial pain and suffering to workers who experience the symptoms. Providing appropriate interventions to assist in reducing risk factors which lead to work-related illness is crucial. Under current Irish health and safety legislation ${ }^{2}$ all workplaces should have a 'Safety Statement' which clearly identifies workplace risks and hazards and details measures to control, reduce or eliminate these risks and hazards. The Irish Health and Safety Authority (HSA) state, 'Stress can be broadly defined as the negative reaction people have to aspects of their environment as they perceive it' $(2010, p 5)$. Stress is considered as part of normal life experience and can be targeted by social situations as well as personal issues. How people cope with stress may depend on their personality, psychology and health. Work-related stress is stress associated with work, the HSA define work-related stress as:

Work-related stress (WRS) is stress caused or made worse by work. It simply refers to when a person perceives the work environment in such a way that his or her reaction involves feelings of an inability to cope. It may be caused by perceived/real pressures/deadlines/threats/anxieties within the working environment. $(2010, p 7)$

The HSA suggest work-related stress can affect people in different ways: mental state; cognitive process; behaviours; and physical symptoms. The effects of work related stress

\footnotetext{
${ }^{2}$ See, Safety, Health and Welfare at Work Act 2005, URL link http://www.irishstatutebook.ie/pdf/2005/en.act.2005.0010.pdf
} 
can be dependent on complexity of other factors such as: age; health; gender; life style; personality; emotional state; well-being. The manifestations of the effects of work-related stress can be observed as changes in behaviour, anger, rage, tearfulness, easily upset and antisocial activities. Several tools have been developed to assess the stress levels of an individual and groups. These tools use standardised factors to compare stress levels against norms. Byrne $(2013$, p75) notes that under the current legislation employers have an obligation to put 'reasonably practicable' measures in place to protect the safety, health and welfare of employees. The HSA note the employer's obligation to reduce risk factors and hazards at work goes beyond good intention and requires active risk assessment strategies. The HSA in its publication Work-Related Stress, Employers Guide states:

...in order to ensure the workplace has safeguards against unreasonable demands, employers should have preventive systems in place. The employer may have the best intentions, but his/her legal duty goes beyond intentions. This is why the HSA promotes the putting in place of risk assessments and control measures so that employers can be assured that their management systems ensure the demands placed on employees are reasonable. $(2005, \mathrm{p} 11)$

Similarly, the Labour Relations Commission Code of Practice, Work-related stress (2005) places the responsibility on the employer to provide reasonable measures to prevent workrelated stress, it states:

Under the agreement, the responsibility for determining the appropriate measures rests with the employer. These measures are carried out with the participation and collaboration of workers and/or their representatives. These measures can be collective, individual or both. They can be introduced in the form of specific measures targeted at identified stress factors or as part of an integrated stress policy encompassing both preventive and responsive measures.

The World Health Organisation (WHO) recognises work-related stress can have an adverse impact on workers' health in the forms of physical, psychological and social well-being. Work-related stress is associated with the organisation of work including; the context, the content, workload, working hours, relationships, role and duties. In a report by WHO (2004) 'Work Organisations and Stress, Protecting Workers' Health' it is noted that

\footnotetext{
${ }^{3}$ This Code of Practice was negotiated and agreed in 2005 by the employers' organisation (IBEC) and the trade unions group (ICTU), facilitated by the LRC.
} 
employers should carry out risk assessments relating to work-related stress and put in place appropriate measure for prevention. The reports states:

A good employer designs and manages work in a way that avoids common risk factors for stress and prevents as much as possible foreseeable problems. (2004, p11)

WHO identify "Organisational Culture", the norms and ways of doing things within a workplace, has a very significant effect on the levels and risks of work-related stress. Organisational culture develops from managements' organisation of work, processes, practices and procedures. WHO notes employers and trade unions should identify risks and preventive measures stating:

Employers, managers and trade union representatives must therefore become aware of the culture of an organisation, and explore it in relation to the management of work stress. If necessary, these parties must engage in culture change activities as an important aspect of improving the management of stress at work (2004, p25)

\section{Management Standard Tool for Work-related Stress}

The development of the current Health and Safety Executive 'Management Standard Tool for Work-Related Stress' derives from the earlier work of Cox (1993) and his taxonomy approach which focused on 'job content' and 'job context'. This approach lead to explorations of coping styles, demands of the job, and whether a person was fit-for-thejob. The Health and Safety Executive funded several research studies into work-related stress during the 1990s. These lead to the development in 1999 of a standards approach. The standards approach was informed from quantitative surveys and psychometric tests. The standards approach identified work-related stress factors such as: control, demand, and role. The Health and Safety Executive (2003) proposed the following seven standardised measures for work-related stress:

- $\quad$ Demands (including such issues as workload, work patterns and the working environment).

- $\quad$ Control (how much say the person has in the way they do their work).

- $\quad$ Support (which includes the encouragement, sponsorship and resources provided by the organisation, line management and colleagues).

- $\quad$ Relationships at work (which includes promoting positive working practices to avoid conflict and dealing with unacceptable behaviour). 
- $\quad$ Role (whether people understand their role within the organisation and whether the organisation ensures that the person does not have conflicting roles).

- $\quad$ Change (how organisational change (large or small) is managed and communicated in the organisation).

- $\quad$ Culture (the way in which organisations demonstrate management commitment and have procedures which are fair and open).

Research by Kerr et al. (2009) further advanced the standardised approach by carrying out a study on the impact of the use of the 'Standards Tool' had in workplaces. Their research validated the seven scales as encompassed by a thirty-five item questionnaire. After lengthy consultation with employers, trade unions and employees, the Health and Safety Executive in 2010 launched its Management Standards Tool and resource pack for use by employers and employees to measure the levels of work-related stress in different workforces. The Management Standards Tool (2010) contains the first six factors listed above. The factor Culture was removed due to poor correlation significance. The Management Standards tool represents a set of conditions which can be used to indicate the levels of work-related stress present in a workplace. The tool is used to both establish baseline data allowing for annualised administration for comparative analysis and as an instrument to stimulate discussion and awareness about work-related stress. It is recommended that the Management Standards tool should be used in combination with the provision of information relating to work-related stress. The employer has an obligation to provide working environments that meet health and safety standards and provide interventions in cases where risks are identified, the employee has a responsibility to bring hazards and risks factors to the attention of the employer.

\section{The Survey Instrument and Method}

The survey instrument developed for this study comprised of three components: (1) an invitation email with an embedded URL link to the survey, (2) an instruction section on how to complete the survey and (3) the survey which had three sections - profile, standardised questions and third-level items.

(1) The invitation email explained the purpose of the survey, noting the reach was initiated by the union to establish the extent of work-related stress in the institutes of technology sector. The email provided an anonymity guarantee. Participants were assured that the tracking setting was switched off and their privacy was protected. 
The email also notified participants that a reminder email would issue in two weeks. The duration and closing date of the survey were detailed.

(2) The instruction section provided information on how to record a response to items in the survey. The estimated time to complete the survey was provided. Participants were informed of the number of sector and items within each section. Participants were notified that by submitting the survey they were giving their consent to the researchers to use their response in the analysis of gathered data.

(3) The survey used an online format, consisting of three sections. Section one comprised of six profile items including; age, gender, place of work, grade, duration of employment and employment type. Section two comprised of the 35 items from the Management Standards tool. Responses were registered on a five point Likert scale. Section three consisted of nine items relating to third-level issues. Open text boxes for observations and comments are provided at the end of sections two and three.

The sample population for the online survey was lecturing staff in the institutes of technology sector. This grade of worker can be considered as professional. The International Labour Organisation (ILO) International Standard Classification of Occupations (2012) would place academic workers into 'Skill Level 4'. Workers with this occupational classification demonstrate 'complex problem solving, decision making and creativity based on theoretical and factual knowledge in specialised field' (p13, 2012). Other types of more qualitative categories are Kerehner et el (1997) 'mind workers' those who utilise their abilities to teach others, or what Horibe (1999) terms 'knowledge workers', those who exercise intellectual capital in their teaching work. Specifically, within the institutes of technology sector the grade lecturer comprises of five subsets: Senior Lecturer III (head of school, senior academic leader, management function), Senior Lecturer II (head of department, academic leader, management functions), Senior Lecturer I Teaching (leading teaching role, research and some administrative functions), Lecturer (career grade position, teaching, research and other functions) and Assistant Lecturer (recruitment grade, teaching research and other functions). In 2014 the Union density was $70 \%$ for TUI members in the respective grades in the institutes of technology sector. The sample method targeted the whole sample population who have an email address and 
access to email during the survey. This sampling approach is akin to 'convenience sampling' (Robson 1993, p141) however, the associated disadvantage regarding representative nature of the findings is greatly mitigated which the targeting of a very high percentage of the whole sample population. The convenience sampling relates specifically to access to email address of the sample population. The response rate target for the survey was set at $30 \%$ of the sample population the institute of technology sector although consideration would need to be taken of the percentage margin of error.

The invitation email which contained the URL link to the online survey was distributed on the $28^{\text {th }}$ November 2014. Two reminders emails were the $8^{\text {th }}$ December and the $13^{\text {th }}$ December 2014. The survey was open for approximately 23 days, closing at $5 \mathrm{p} . \mathrm{m}$. on the $20^{\text {th }}$ December 2014. Some issues were reported relating to accessing the online survey from different browsers/platforms (Chrome, Firefox, Android) and machines (tablets, phones). In all cases the issue was resolved and the participant gained access to the survey.

\section{Survey Responses}

In total, the number of responses to the online survey was $n=1,131$. Table 1 presents the number of responses received from each workplace (loT).

\begin{tabular}{lrrr}
\hline Workplace & $\mathbf{N}$ & \% & Valid\% \\
\hline Athlone IT & 78 & 6.9 & 6.99 \\
Blanchardstown IT & 38 & 3.36 & 3.41 \\
Carlow IT & 78 & 6.9 & 6.99 \\
Dublin IT & 197 & 17.42 & 17.65 \\
Cork IT & 155 & 13.7 & 13.89 \\
Dundalk IT & 86 & 7.6 & 7.71 \\
Dun Laoghaire IT & 43 & 3.8 & 3.85 \\
Galway/Mayo IT & 115 & 10.17 & 10.3 \\
Sligo IT & 44 & 3.89 & 3.94 \\
Tralee IT & 50 & 4.42 & 4.48 \\
Tallaght IT & 51 & 4.51 & 4.57 \\
Waterford IT & 80 & 7.07 & 7.17 \\
St Angela's & 5 & 0.44 & 0.45 \\
Letterkenny IT & 38 & 3.36 & 3.41 \\
Limerick IT & 58 & 5.13 & 5.2 \\
Missing & 15 & 1.33 & 0 \\
Total & 1131 & 100 & 100 \\
\hline \multicolumn{1}{c}{ Table 1 Number of responses per workplace including missing data }
\end{tabular}

The three highest number of responses received came from Dublin Institute of Technology at $17.6 \%(n=197)$, Cork IT $13.8 \%(n=155)$ and Galway/Mayo IT 10.3\% ( $n=115)$. The 
distribution of responses per workplace was generally in line with actual union membership sizes. There were some exceptions. A higher number of responses was expected from Waterford IT $(7.1 \%, \mathrm{n}=80)$ this is a relatively large workplace similar in size to Cork IT. Conversely the number of responses from Athlone IT which is a medium size workplace was much higher than expected at $6.9 \%(n=78)$. The number of responses from St Angela's was much lower than expected at .45\% $(n=5)$, whilst this is a small workplace the number of responses is too-low to make any kind of statistical analysis meaningful.

The target percentage response rate of $30 \%$, including the margin of sample error (5\%), was derived from Nulty (2008) study of response rates for paper-based surveys as compared to online surveys. Paper-based surveys in general have an average response rate of $56 \%$ whereas, online surveys have an average response rate of $33 \%$. Nulty notes the differences between an 'adequate response rate' and a 'required response rate'. An adequate response rate can be achieved with 'convenience sampling' whereas a required response rate necessitates 'randomised sampling'. Nulty suggests that using 'liberal conditions' with a sample error of $10 \%$ the confidence level could be set at $80 \%$ whereas, 'stringent conditions' with a sample error of $3 \%$ could lead to a confidence level of $95 \%$. In conjunction with the margin of sample error, the required response rate needs to be established for different sizes of sample populations. Based on studies of student populations and response rates for randomised sampling techniques, Nulty suggests for 2,000 students under 'liberal conditions' the required response rate is $1 \%$, compared to $25 \%$ under 'stringent conditions'. In consideration of Nulty's average response rate of 33\% for online surveys, and the suggested $25 \%$ required response rate for 2,000 students using randomised sampling; this study has set an adequate response rate at $30 \%$ using a convenient sampling approach of the sample population, with a sample error of $5 \%$ which should provide for an estimated confidence level of $90 \%$. The rationale for these changes include; the geographical distribution of the sample population, the unknown number of inactive email accounts or incorrect email addresses, the unknown number of members on leave or out due to illness during the survey period and other minor technical issues. The response rates for the total sample per workplace are presented in Table 2. 
Target response rate including margin of error of $5 \%$

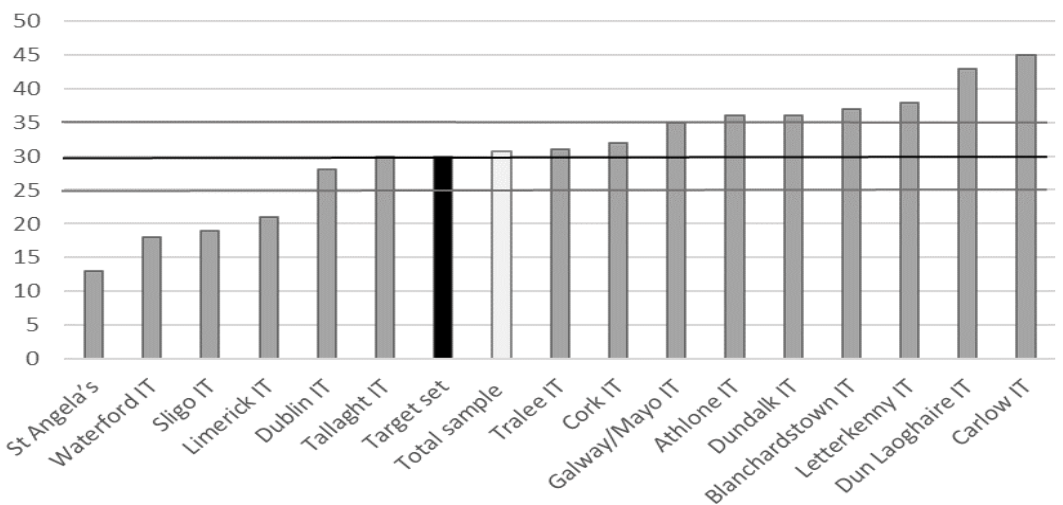

Table 2 Response rate targets all workplaces

The response rate for the total sample was $30.8 \%$. This is in line with the target response rate set at $30 \%$. When the response rate is disaggregated per workplace there is evident divergence from the target response rate. All but four workplaces failed to meet the minimum threshold of $25 \%$ response rate $(30 \%+/-5 \%$ as sample margin of error). Six workplaces exceeded the target response rate (Athlone, Dundalk, Blanchardstown, Letterkenny, Dun Laoghaire and Carlow). Carlow reached the highest response rate at $45 \%$. Five workplaces are within the target range of 25\%-30\% (Dublin, Tallaght, Tralee, Cork and Galway/Mayo), and four workplaces did not reach the lower end of the sample of error of 25\% (St Angela's, Waterford, Sligo and Limerick) although Limerick was closest to the threshold at $21 \%$. In general, the response rate achieved was adequate and met the identified target level. Of the four workplaces that did not reach the minimum response rate threshold, St. Angela's is too low to produce an individual report as the confidence level would be minimal. However, the numbers of responses in the other three are sufficient enough to merit an individual report while the desired confidence level may not have been achieved. The responses are enough to give a good indication of the opinions of Union members.

There were a high level of responses to the item 'Gender' with $96.5 \%(n=1,091)$ of respondents indicating a preference and only $3.5 \%(n=40)$ chose not to indicate their gender (see Table 3). Excluding the missing responses $(n=40)$ the gender profile of the respondents was Female $49 \%$ and Male 51\%. This result is similar to the Union membership profile for the institutes of technology sector which is Females $48 \%$ and Males $52 \%$. 


\begin{tabular}{lrrr}
\hline Gender & $\mathbf{N}$ & $\mathbf{\%}$ & Valid \\
\hline Female & 533 & 47.13 & 48.85 \\
Male & 558 & 49.34 & 51.15 \\
Missing & 40 & 3.54 & 0 \\
Total & 1131 & 100 & 100 \\
\hline \multicolumn{4}{c}{}
\end{tabular}

Responses to the item Age Range was $n=1,126$. The majority of the response group $65 \%$ indicated they are in the mid-career age range (41-55), 18\% indicated they are in the early career age range (26-40) and $17 \%$ indicated then are in the late career range (51-65).

\begin{tabular}{lrrr}
\hline Age range & $\mathbf{N}$ & $\mathbf{\%}$ & Valid \% \\
\hline $26-30$ & 7 & 0.62 & 0.62 \\
$31-35$ & 64 & 5.66 & 5.68 \\
$36-40$ & 136 & 12.02 & 12.08 \\
$41-45$ & 260 & 22.99 & 23.09 \\
$46-50$ & 250 & 22.1 & 22.2 \\
$51-55$ & 232 & 20.51 & 20.6 \\
$56-60$ & 125 & 11.05 & 11.1 \\
$61-65$ & 51 & 4.51 & 4.53 \\
$66+$ & 1 & 0.09 & 0.09 \\
Missing & 5 & 0.44 & 0 \\
Total & 1131 & 100 & 100 \\
\hline
\end{tabular}

The majority of respondents $90 \%$, indicated the employment type as Permanent Wholetime (PWT) and Contract of Indefinite Duration (CID). The Union does not distinguish between these two grades as they both represent permanent contracts of employment. The rest of the respondents indicated their employment type with their institute is either a Fixed-term $6.5 \%(n=73)$ or a Part-time $3.5 \%(n=40)$. Within the response group the proportion of permanent employment (PWT/CID) compared to temporary employment (fixed-term/part-time) is 9:14 the average proportion ratio for permanency and temporary in the institute of technology sector is 8:2. The response group sample is out-of-line with the Union membership ratio of permanent to temporary in the third-level sector of members is 7:3. Table 5 gives the full details on the employment type of the response group.

\footnotetext{
${ }^{4}$ In some institutes it can be as low as 7.5:2.5. The union is engaged in an active campaign to increase permanency in the sector. Under the Haddington Road Agreement the reference period for a contract of indefinite duration (CID) entitlement was reduced from legislative requirement of 4 years to a reduce period of 3 years. For second level teachers the reference period was reduced to 2 years as recommended by the Ward Report. For third level an Expert Group has been established to report on casualisation and a report is expected in 2015.
} 


\begin{tabular}{lrrr}
\hline Employment Type & N & \% & Valid\% \\
\hline Permanent Whole & & & \\
Time & 927 & 81.96 & 83.82 \\
CID & 66 & 5.84 & 5.97 \\
Fixed Term & 73 & 6.45 & 6.6 \\
Part Time & 40 & 3.54 & 3.62 \\
Missing & 25 & 2.21 & 0 \\
Total & 1131 & 100 & 100 \\
\hline & Table 5 Employment type of Respondents
\end{tabular}

Table 6 details the number of years the response group indicated they are employed in their institute. The majority $34 \%(n=380)$ indicated they are employed for $11-15$ years. In terms of those new to the profession $8.5 \%(n=96)$ indicated they are employed between 15 years compared to $1.16 \%(n=13)$ who have more than 36 years' service in the profession.

\begin{tabular}{lrrr}
\hline Years in employment & $\mathbf{N}$ & $\mathbf{\%}$ & Valid\% \\
\hline 1-5 years & 96 & 8.49 & 8.58 \\
6-10 years & 197 & 17.42 & 17.61 \\
11-15 years & 380 & 33.6 & 33.96 \\
16-20 years & 195 & 17.24 & 17.43 \\
21-25 years & 124 & 10.96 & 11.08 \\
$26-30$ years & 70 & 6.19 & 6.26 \\
$31-35$ years & 44 & 3.89 & 3.93 \\
$36-40$ years & 12 & 1.06 & 1.07 \\
over 40 years & 1 & 0.09 & 0.09 \\
Missing & 12 & 1.06 & 0 \\
Total & 1131 & 100 & 100 \\
\hline \multicolumn{2}{c}{ Table 6 Number of years the Respondent is employed in the Sector }
\end{tabular}

The grade profile of the respondent group (see Table 7) is broadly in line with Union membership for third-level. Of the respondents $14 \%(n=155)$ are Assistant Lecturers, 74.5\% $(n=822)$ are Lecturers and Senior Lecturer grades represented $10.5 \%(n=121)$, only $.5 \%(n=6)$ indicated they are researchers.

\begin{tabular}{lrrr}
\hline Grade & $\mathbf{N}$ & $\mathbf{\%}$ & Valid\% \\
\hline Assistant Lecturer & 155 & 13.7 & 14.04 \\
Lecturer & 822 & 72.68 & 74.46 \\
Senior Lecturer (Teaching) & 43 & 3.8 & 3.89 \\
Senior Lecturer II & 59 & 5.22 & 5.34 \\
Senior Lecturer III & 19 & 1.68 & 1.72 \\
Researcher & 6 & 0.53 & 0.54 \\
Missing & 27 & 2.39 & 0 \\
Total & 1131 & 100 & 100 \\
\hline
\end{tabular}


The profile of the respondent group (workplace, gender, and grade) is proportionate to the membership profile for the institutes of technology sector. However, the employment type ratio (Permanent: Temporary) for respondents 9:1 differs from the membership at $7: 2$.

\section{Survey Findings}

In this section findings from the survey are presented for the total respondent group. The findings are then disaggregated for each workplace (institute). The findings are presented in two separate parts (1) Management Standards tool and (2) Third-level items. The analysis of the Management Standard questionnaire is mainly confined to the Health and Safety Executive framework, although additional analysis and observations are provided. The Management Standards Questionnaire comprised of seven 'Stressors' which contained thirty-five 'Factors' summarised below. Participants completing the questionnaire are requested to reflect on the workplace experience and choose responses which best indicate their opinions to each factor on five point Likert scales.

\begin{tabular}{|c|c|}
\hline Stressors & Factors \\
\hline Demand & $\begin{array}{l}8 \text { factors including; demands from different groups, unachievable } \\
\text { deadlines, work intensely, neglect tasks, insufficient breaks, working } \\
\text { long hours, working very fast, unrealistic time pressure. }\end{array}$ \\
\hline Control & $\begin{array}{l}6 \text { factors including; deciding to take a break, say on speed of work, } \\
\text { decide how to do work, decide what to do, say over the way to work, } \\
\text { flexible working time. }\end{array}$ \\
\hline $\begin{array}{l}\text { Management } \\
\text { support }\end{array}$ & $\begin{array}{l}5 \text { factors including; supportive feedback, rely on line manager, talk } \\
\text { to line manager, support during emotionally demanding work, } \\
\text { encouragement from manager. }\end{array}$ \\
\hline Peer support & $\begin{array}{l}4 \text { factors including; colleagues help, get support from colleagues, get } \\
\text { respect, colleagues listen. }\end{array}$ \\
\hline Relationships & $\begin{array}{l}4 \text { factors including; subject to harassment, friction between colleagues, } \\
\text { subject to bullying, strained relationships. }\end{array}$ \\
\hline Role & $\begin{array}{l}5 \text { factors including; clear what is expected, know how to get things } \\
\text { done, clear of duties, clear about goals, and understand work and } \\
\text { organisation. }\end{array}$ \\
\hline Change & $\begin{array}{l}3 \text { factors including; can question manager about change, staff are } \\
\text { consulted about change, clear about changes made. }\end{array}$ \\
\hline
\end{tabular}

The rationale for the survey is to establish current baseline data from the sample group as to the level of work-related stress experienced. Annual follow-up surveys will enable comparative analysis and whether work-related stress risks have increased or decreased. The results are presented as percentage scores on the risk scale for each set of factors within each of the seven Stressors, followed by an analysis of the average means scores of each of the seven stressors. Comparative analysis is presented related to gender, grade 
and employment type analysis. Finally, results for each workplace will be presented using the average means score approach. Results are displayed for each individual Factor and Stressor. Results for individual Factors are presented in percentage format on a five point scale (Very low, Low, Moderate, High and Very high). Results for a Stressor consist of calculating the average means scores of Factors within the Stressor, placing these on a risk indicator (Red=Very high, Orange=High, Yellow=Moderate and Green =Low).

\section{Results for Factors per Stressor}

The results for the thirty-five factors within the Management Standards questionnaire are presented in this section. The responses to each factor are grouped under their associated Stressor. In each case results are provided in percentage format for each factor and the five choices presented in the questionnaire. The results for the five choices are placed on a standardised five risk scale (Very low, Low, Medium, High and Very High). The intensity of the risk is ascertained by examining the percentage value of each choice within the factor.

The Stressor 'Demand' explores participant's opinions on seven Factors associated with work: deadlines, work tasks, intensity of work, speed of work tasks, breaks, duration, amount of work and competing demands.

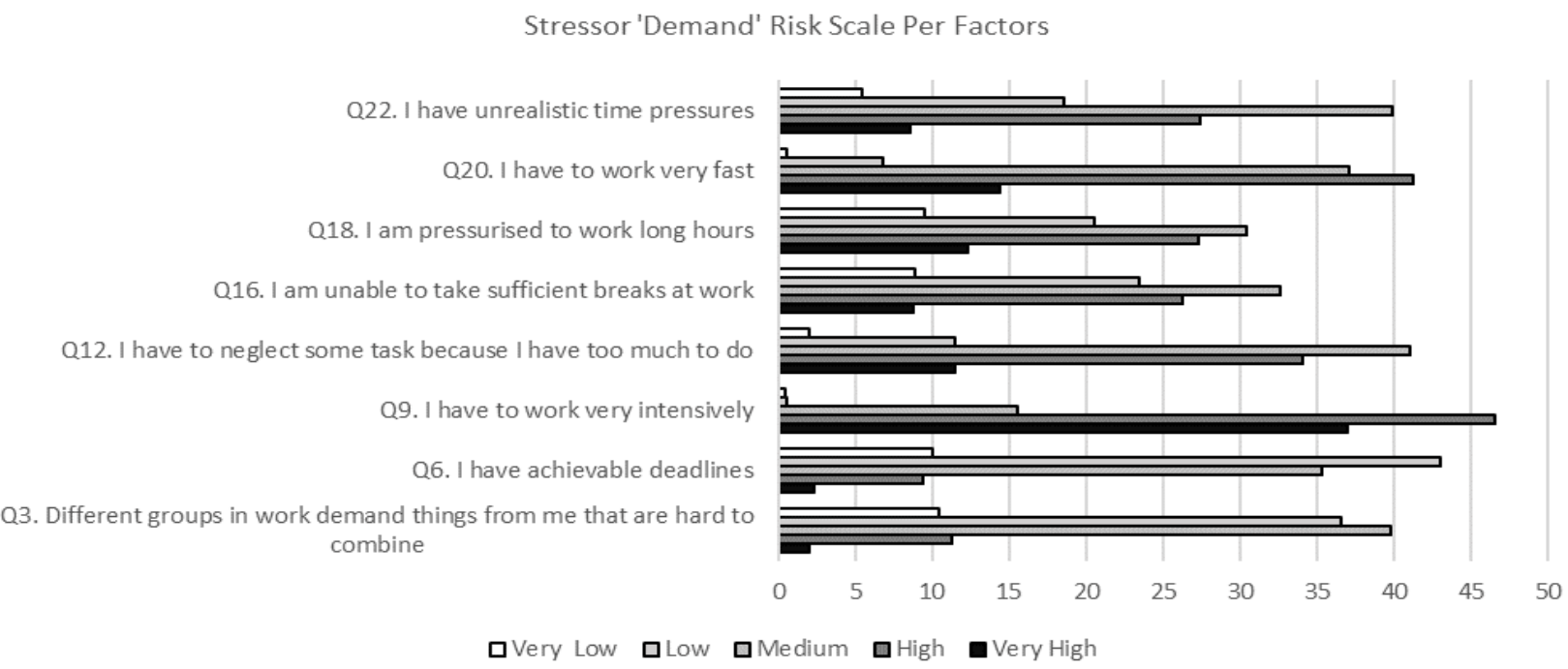

Figure 1 Responses in percentages to Factors in Stressor Demand

The full list of Factors associated with the Stressor Demands are presented in Figure 1. Results are detailed in percentage format on the five-point risk scale from Very Low to Very High. The factors identified as having elevated levels of risk contributing to work-related 
stress are: 'I have to work very intensively' at $37 \%$ Very high and $46 \%$ High, 'I have to work very fast' at $15 \%$ Very high and $41 \%$ High and 'I am pressurised to work long hours at $13 \%$ Very high and $27 \%$ High.

The Stressor Control consists of six Factors which inquire into how much influence a worker has relating to their working time, how they work, what to work on, how to work, speed of work and when to have a break. Respondents indicated they had relative levels of control over their work which result in decreased levels of risk of experiencing work-related stress. This is evident in the high percentage scores for risk indicators Low and Very low in some Factors such as; 'I have some say in the way I work' 10\% Very low and 59\% Low, 'My work time can be flexible' at 5\% Very Low and 35\% Low, 'I can decide when to have a break' at $18 \%$ Very low and $32 \%$ Low.

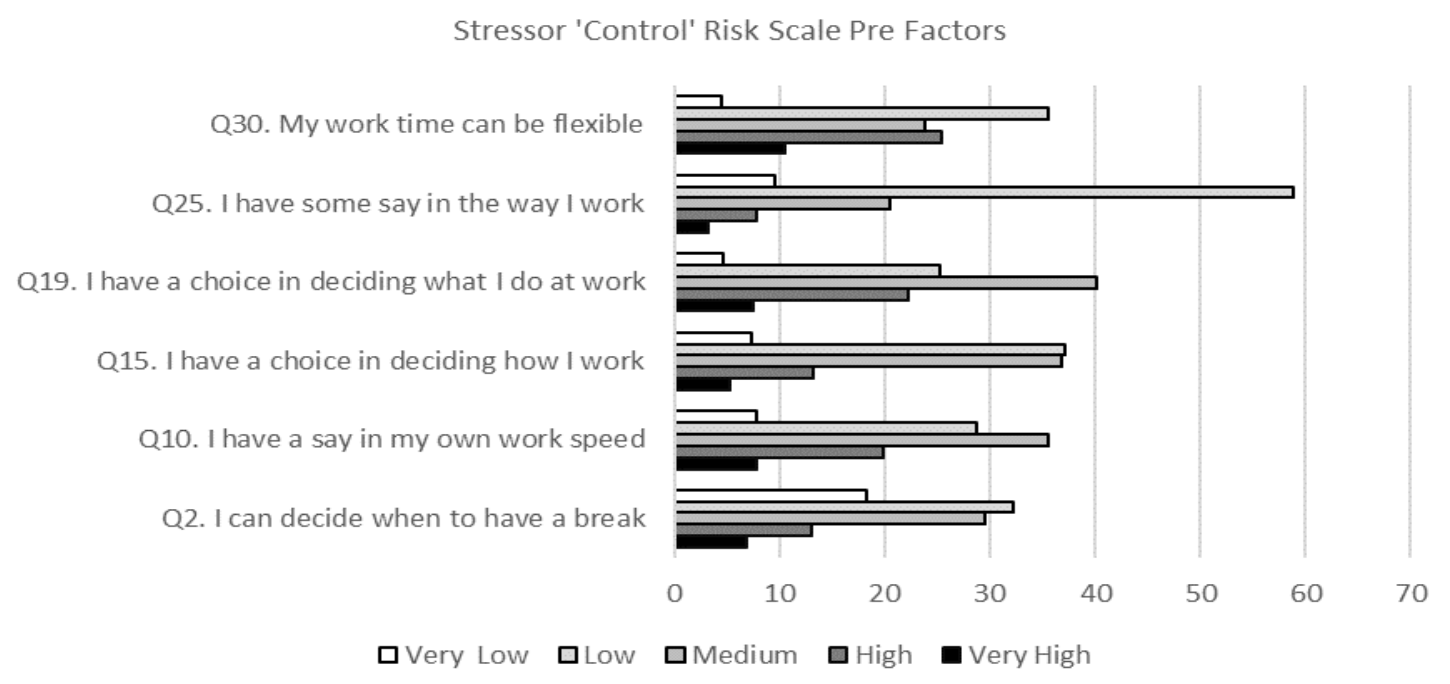

Figure 2 Response in percentages to Factors in Stressor Control

The Stressor Managers' Support explores the extent workers consider managers provide support on a range of issues such as encouragement, emotionally, discussions, problem solving and feedback. Respondents indicated differential levels of risk. Respondents considered their manager encouraged them at work (Q35 Low 35\%, Medium 34\%), could talk to their manager about work that upsets them (12\% Very low and $38 \%$ Low). In comparison high risk was associated with lack of feedback ( $28 \%$ Very high, $38 \%$ High) and assistance with work problem (14\% Very high, 23\% High and 30\% Medium). 
Q35. My line manager encourages me to work

Q33. I am supported through emotionally challenging work

Q29. I can talk to my line manager about something that has upset or annoyed me about work

Q23. I can rely on my line manager to help me with a work problem

Q8. I am given supportive feedback on the work I do

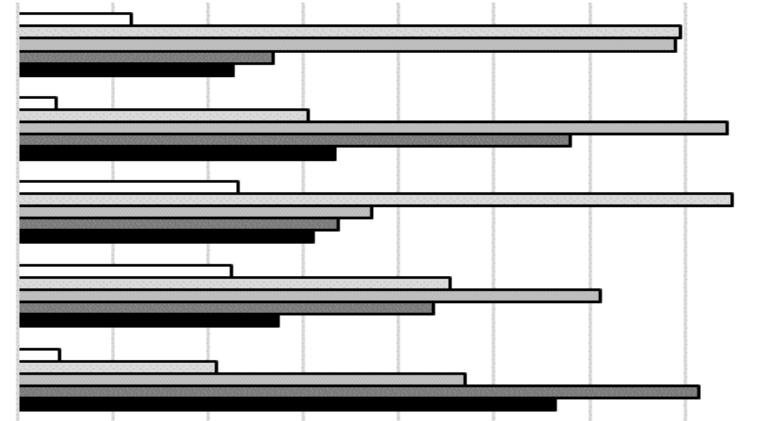

口Very Low $\square$ Low $\square$ Medium $\square$ High $\mathbf{a V e r y H i g h}$

Figure 3 Response in percentage to Stressor Managers' Support

The Stressor Peer Support explored four factors such as work colleagues; listening, respect assistance and help. The respondents indicated relatively high levels of support which is evident in the high percentage responses to Very Low and Low indicators. Respondents consider colleagues listened to them (51\% Low), received the respect deserved at work (45\% Low), get help when needed from colleagues (45\% Low). Although respondents indicated a risk factor (35\% Medium) to 'If work gets difficult, my colleagues will help me'.

Stressor 'Peer Support' Risk Scale Per Factor

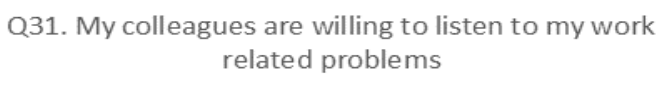

Q31. My colleagues are willing to listen to my work related problems

Q27. I receive the respect I deserve from my colleagues

Q24. I get help and support I need from my colleagues

Q7. If work gets difficult, my colleagues will help me

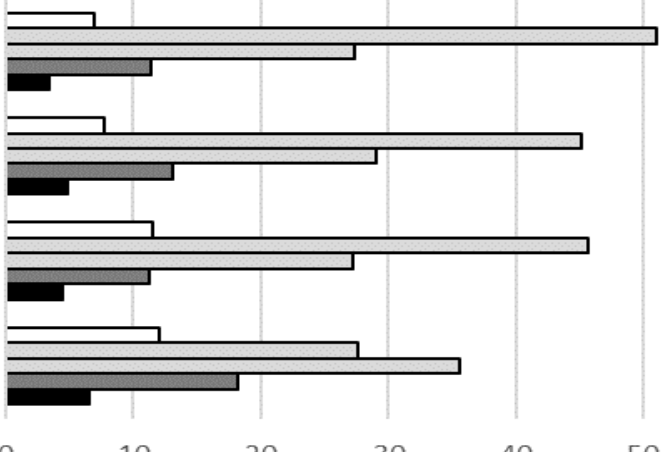

口Very Low $\square$ Low aMedium aHigh $\mathbf{a V e r y H i g h}$

Figure 4 Responses in percentages for Factors in Stressors Peer Support

The Stressor Relationships consisted of four Factors which explored; strained relationships, bullying, friction between colleagues and harassment. Respondents indicated work relationships are strained (10\% Very High, 31\% High and 26\% Medium), also friction and anger amongst colleagues received a strong Medium score of 38\%. Respondents did not consider they are bullied at work. 39\% indicated Very Low and 31\% Low risk. Similarly 
harassment at work was identified as relatively low with 30\% Very Low risk and 35\% Low risk.

Stressor 'Relationships' Risk Scale Per Factors

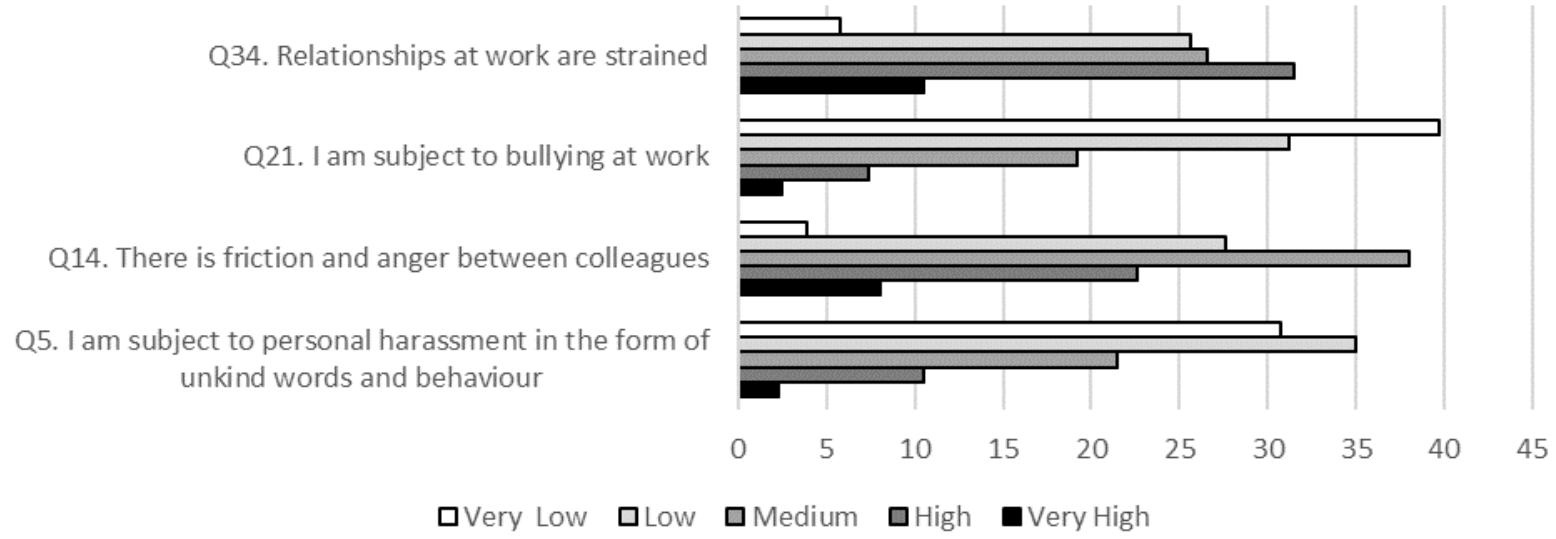

Figure 5 Responses in percentages for Factors in Stressor Relationships

The Stressor Role explored five Factors including, understanding work aims, clear about goals and objectives, clear about duties, can get the job done and clear about what is expected. Respondents indicated low risk factors relating to their roles and duties (20\% Very low, 45\% Low), they know how to get their job done (30\% Very low risk, 55\% Low risk) and are clear of what was expected of them (23\% very low risk and $48 \%$ Low risk). However, there was divergence to the Factors which indicated high risk of work-related stress such as; 'I understand how my work fits into the overall aim...' elevated risk at 9\% Very high 20\% High and 35\% Medium and 'I am clear about the goals and objectives...' strong risk at 11\% Very High, 24\% High and 33\% Medium risk.

\section{Stressor 'Role' Risk Scale Per Factors}

Q17. I understand how my work fits into the overall aim of the institute

Q13. I am clear about the goals and objectives of my department/school

Q11. I am clear what my duties and responsibilities are

Q4. I know how to go about getting a job done

Q1. I am clear what is expected of me at work

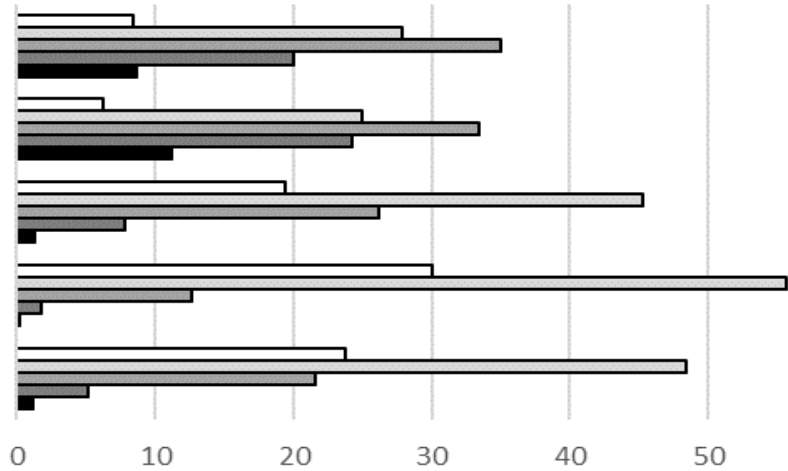

$\square$ Very Low $\square$ Low $\square$ Medium $\square$ High $\mathbf{a V e r y H i g h}$ 
The Stressor Change consisted of three Factors exploring issues such as how changes effects work parties, consultation about change and opportunities to discuss change. Strong elevated risk levels are identified by respondents to these Factors. Respondents are not clear how changes impacted on their work practices. As such, risk levels are evaluated at $19 \%$ Very high, $40 \%$ High and $25 \%$ Medium. Respondents did not consider that staff are consulted about Change risk levels 34\% Very High and 39 High. In addition, respondents did not have sufficient opportunities to discuss change with their managers which lead to evaluated risk levels of $21 \%$ Very High and $30 \%$ High.

\section{Stressor 'Change' Risk Scale Per Factor}

Q32. When changes are made at work, I am clear how they will work in practice

Q28. Staff are always consulted about change at work

Q26. I have sufficient opportunities to question managers about change at work

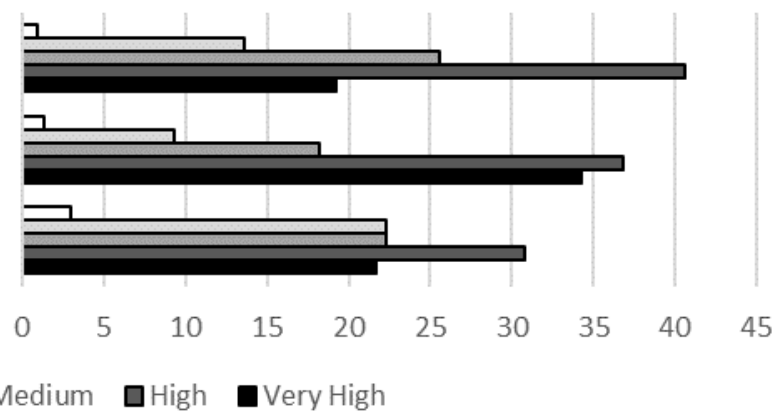

Figure 7 Responses in percentages for Factors in Stressor Change

Analysis of the seven Stressors for the total response group is provided in this section. The results are detailed as average mean scores based on the scores of all Factors within a Stressor. It should be noted that some Factors are deliberately constructed with a reverse scale, and that this effects the calculation of the average mean score for the Stressor. Comparative analysis is provided for gender, employment type and grade. Figure 8 provides the means scores as maximum, average and minimum. The risk indicator comprises of an easy guide; Red=Very high, Orange=High, Yellow=Moderate and Green=Very low. The average means score range for risk indicators is presented in Table 9.

\begin{tabular}{lll}
\hline \multicolumn{2}{c}{ Risk Indicator Scale } \\
\hline Red (Mean score 0.00 to 1.24$)$ & $=$ Very high risk \\
Orange (Mean score 1.25 to 2.49$)$ & $=$ High risk \\
Yellow (Mean score 2.50 to 3.74) & $=$ Moderate risk \\
Green (Mean score 3.75 to 5.00) & $=$ Low risk \\
\hline
\end{tabular}

Table 9 Risk Scale for Average Means Scores

Respondents identified the several stressors which had elevated levels of risk to cause work-related stress. Stressor 'change' at work had an average means score of 2.32 this is an Orange indication (High Risk). Stressor 'demand' had an average means score of 2.69, 
Yellow indicator (Moderate risk), although there were substantial differences between the minimum mean Very High Risk and the maximum mean at Very Low Risk. Stressor 'Managers' support' was identified as Yellow (Moderate risk) at an average mean score of 2.8. Respondents identified Stressors; 'relationships', 'peer support' and 'role' all indicated Yellow (Moderate risk) although there were substantial differences between the minimum, average and maximum mean scores (see figure 8).

\section{Stressors Means Scores, Maximun, Average, Minimun}

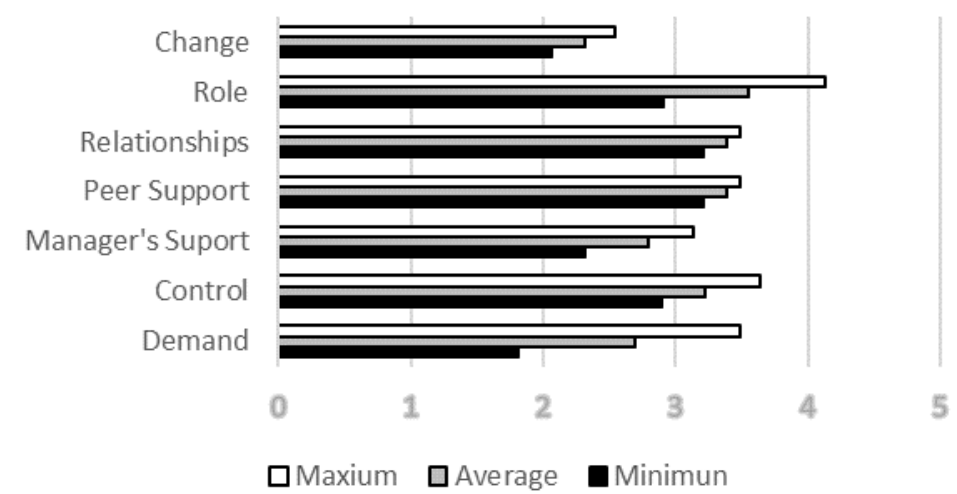

Figure 8 Mean scores for seven Stressors

The seven stressors disaggregated by gender (male-female) is presented in Figure 9. There are minimal differences but not enough to place either gender into another risk category.

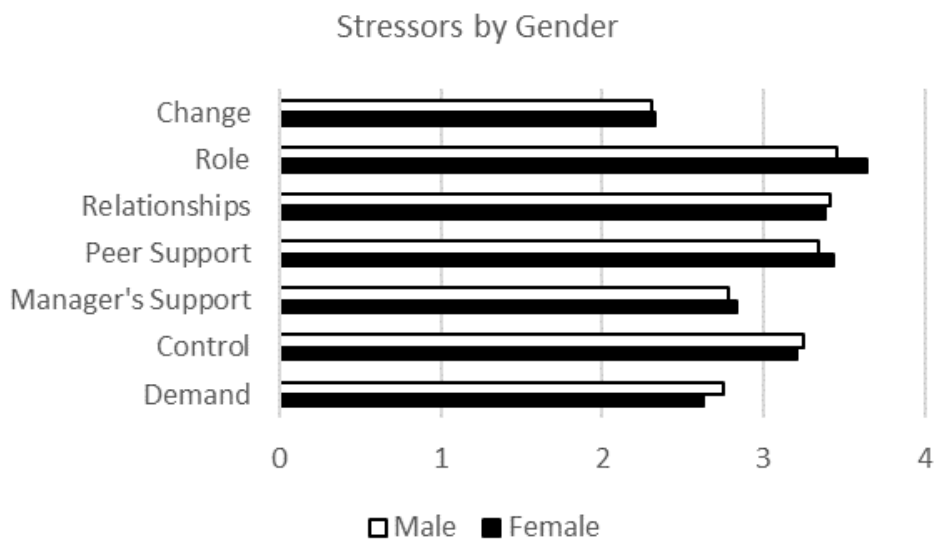

Figure 9 Mean scores for Stressor by gender

When the stressors are disaggregated by 'grade' (Figure 10) there is some difference in total average means scores for Stressors: Role, Relationships, Peer Support and Demand, although in the main, the differences were not enough for reclassification into another indicator band. There is evidence of more divergence between 'grades' in the remaining 
three stressors: 'Change'; Senior Lecturer grades indicate Yellow (Moderate risk 2.67) compared to Lecturer and Assistant Lecturer who indicated Orange (High risk, 2.4, 2.5). 'Managers support'; Senior Lecturers indicated Yellow (Moderate Risk, 3.53) while Assistant Lecturers and Lecturers indicated a stronger Moderate risk (2.92, 2.74). Control: Senior Lecturers at Moderate Risk (3.53) while Assistant Lecturers and Lecturers were at Medium risk $(3.26,3.18)$. In general the Senior Lecturer grade reported lower levels of risk of work-related stress compared to the other two grades.

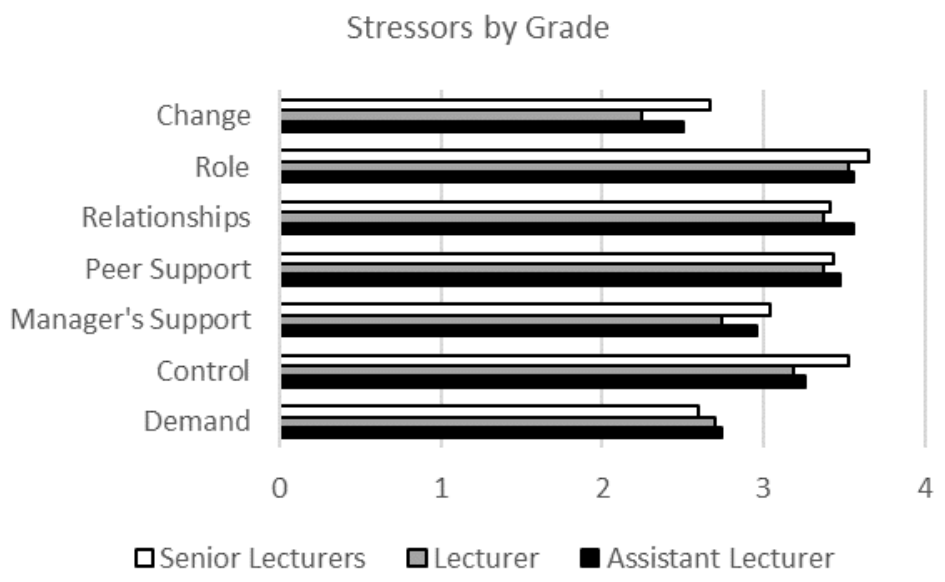

Figure 10 Means scores for Stressors by Grade

Figure 11 shows the disaggregation of data by employment type. In general, there is minimum divergence between employment types (Permanent Whole-time and Parttime/Fixed-term), although divergence is apparent for the Stressor 'Role' with PWT registering a strong yellow moving towards Green (Moderate Risk 3.54) compared to PT/FT reporting a weak Yellow close to the Orange band (Moderate Risk 2.61).

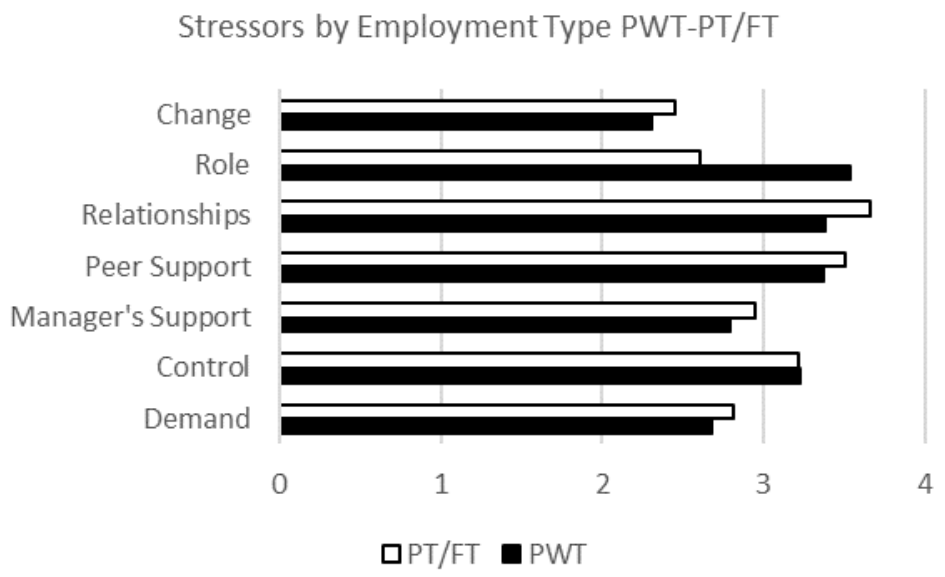

Figure 11 Mean scores of Stressor by Employment type 


\section{Comparison between Institutes per Stressor}

When the data are disaggregated per workplace for the Stressor Demand (see Figure 12), the distribution of results are confined to two risk categories: Orange (High risk) in Tallaght 2.45. All other workplaces are within the Yellow band (Moderate risk) Carlow IT indicated the strongest Moderate at 2.56 while Galway/Mayo IT indicated the weakest Moderate risk at 2.87 .

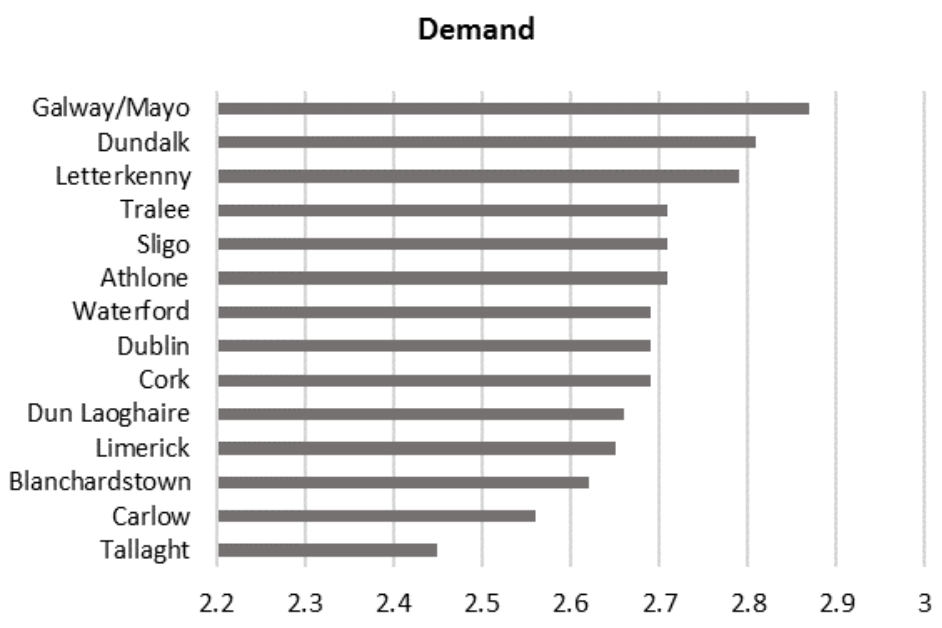

Figure 12 Comparison of means scores Stressor Demand by all workplaces

Figure 13 shows the disaggregated data per workplace for the Stressor Control. Whilst there is divergence in means scores per workplace, the difference is not significant enough to cross over into other risk categories. All workplaces indicated Yellow (Moderate risk), Galway/Mayo workplace indicated a weak Moderate risk at 3.5 compared to Limerick's stronger Moderate risk at 2.99.

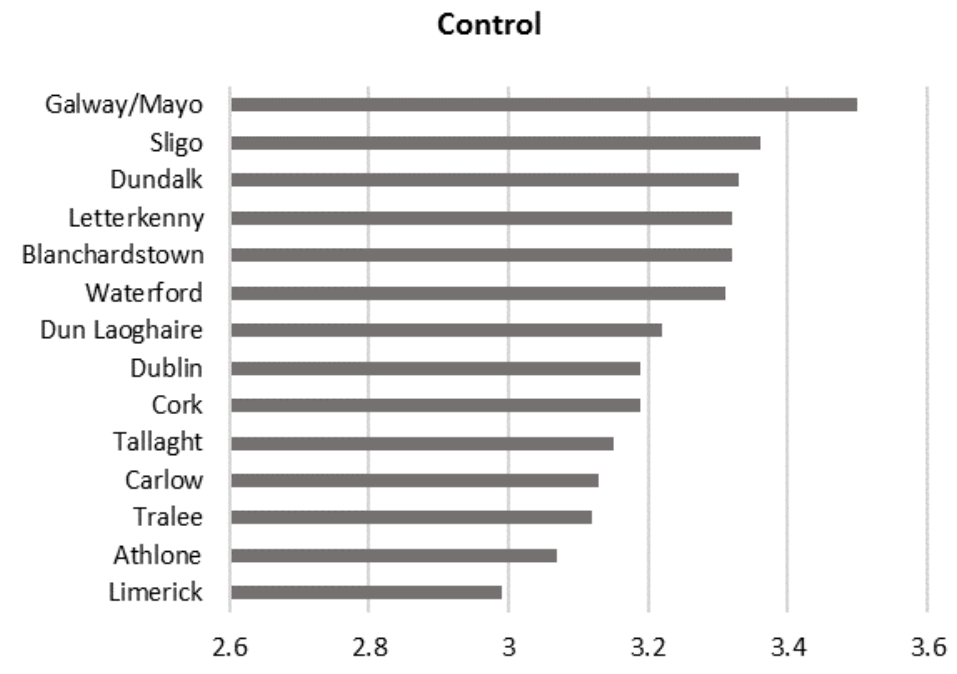

Figure 13 Comparison of means scores Stressor Control by all workplaces 
The disaggregated data for the stressor Managers' Support is presented in Figure 14. All but one workplace indicated Yellow band (Moderate risk), Limerick reported Orange (High risk, 2.4).

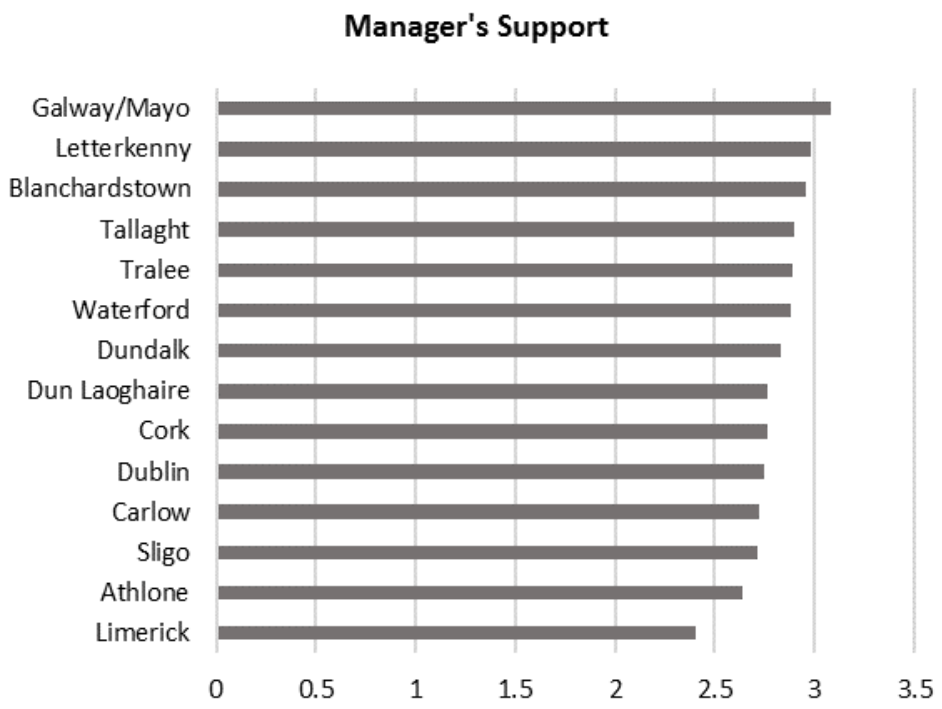

Figure 14 Comparison of means scores Stressor Managers support by all workplaces

When data is disaggregated for stressor Peer Support (see figure 15) all workplaces indicated Yellow (Moderate risk). Carlow indicated a weak Moderate risk at 2.71, whilst Tallaght indicated a strong Moderate risk at 2.63.

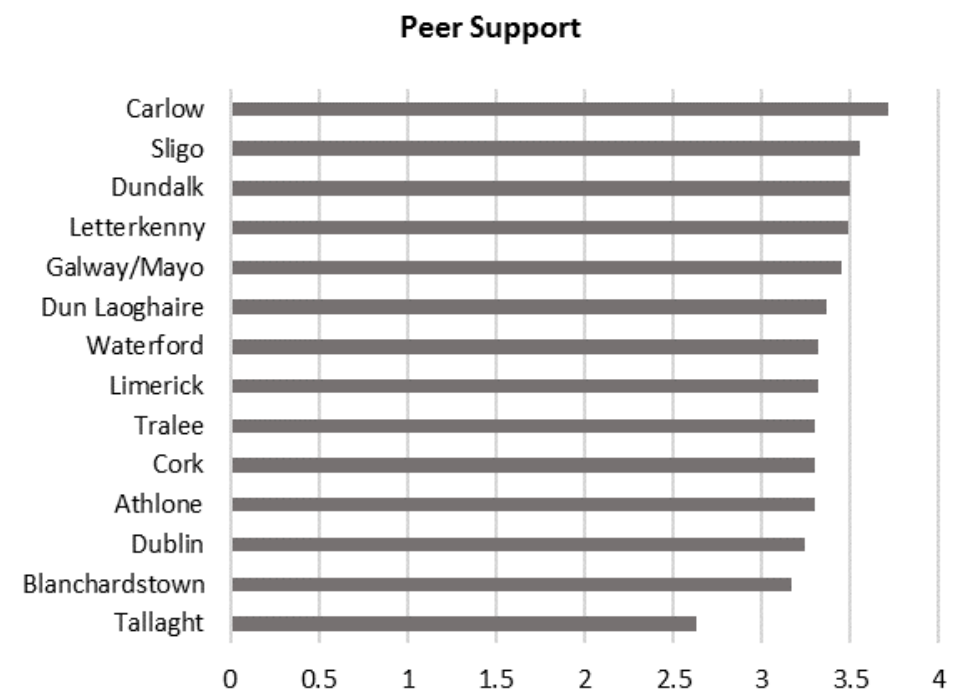

Figure 15 Comparison of mean scores Stressor Peer Support by all workplaces

Figure 16 shows the disaggregated scores per workplace for the Stressor Relationships. All workplaces indicated the Yellow band (Moderate risk). The Dun Laoghaire workplace indicated 3.11 compared to a weak Moderate risk for the Galway/Mayo Workplace 3.68. 


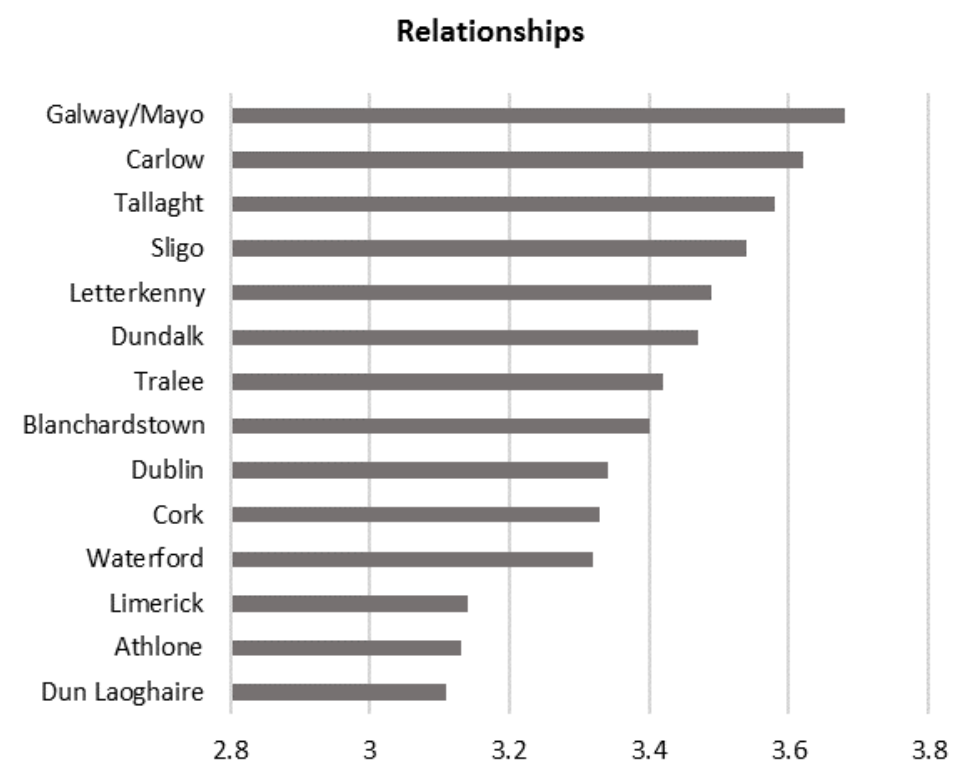

Figure 16 Comparison of mean scores Stressor Relationship by all workplaces

When data are disaggregated per workplace for the stressor Role (see figure 17) all but two workplaces are classified within the Yellow band (Moderate risk). Both Galway/Mayo and Letterkenny indicated Green (Low risk) at 3.76 and 3.78.

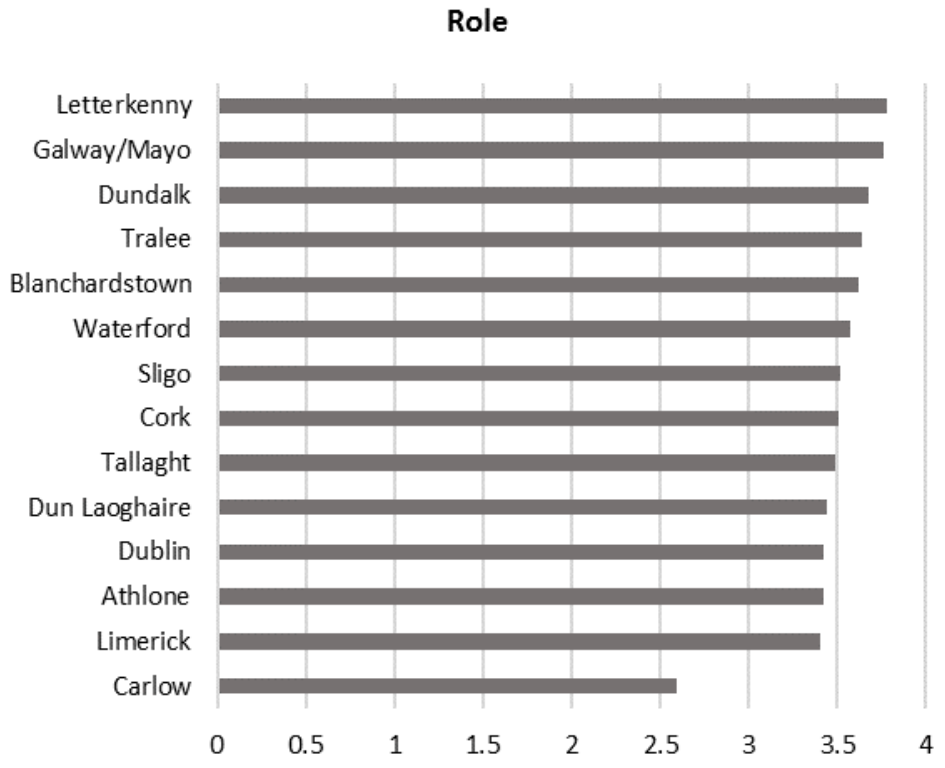

Figure 17 Comparison of mean scores Stressor Role by all workplaces

Figure 18 details the disaggregated data per workplace for the stressor Change. Two workplaces registered Yellow band (Moderate risk) Galway/Mayo and Letterkenny. All other workplaces indicated the Orange band (High risk) the strongest indication was from Limerick at 2.02. 


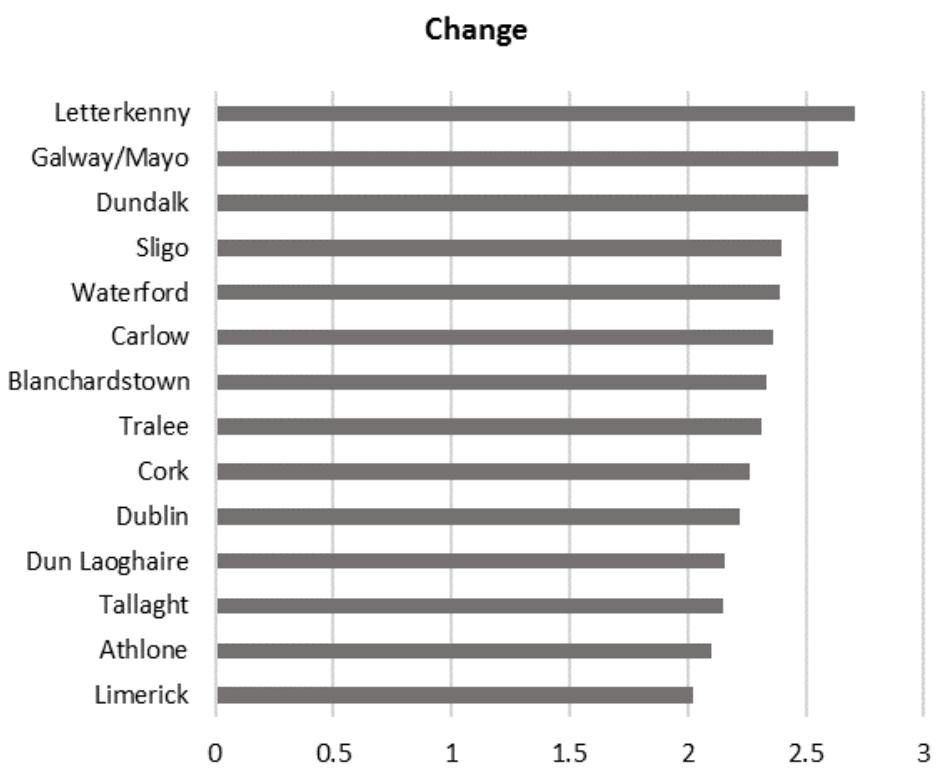

Figure 18 Comparison of means scores Stressor Change by all workplaces

The Stressor that registers the highest risk factor was 'Change'. This incorporates the lack of consultation, lack of input into decisions and lack of clarity about changing work practices. To reduce the risk factor employers would have to engage in a more active consultation processes with workers, seeking their involvement and participation in decision-making and the change process. The Stressor 'Demand' registered moderate risk, this includes factors associated with work tasks, deadlines and pressure to get work done. To reduce the risk level employers would have to put in place measures providing for reasonable deadlines and times to achieve tasks, reduce unrealistic requirements to work long hours arising from excessive workloads and provide for sufficient break and restperiods. The stressor Managers' Support registered moderate risk. This factor includes items such as feedback, encouragement, support, and understanding. To reduce the level of risk, managers could utilise a more collegial style of engagement appropriate for higher education, improve listening skills, and provide constructive feedback and encouragement. The stressor Control also registered moderate risk, this factor included items relating to control over time and work practices. To reduce this risk, employers would have to put in place measures that provide for staff discretion on allocating time to tasks and make accommodations for staff proposed solutions to work process. The stressor Relationships registered a low risk, this includes harassment, bullying and friction between colleagues. To reduce the risk employers should have up-to-date policies and procedures to protect staff in the workplace including holding information workshops on dignity and respect for both 
staff and managers. The stressor Role registered a low risk, this included work duties, goals and knowledge. To reduce this risk employers should clearly identify the aims, goals and functions of the work process and involve staff in the development of same. The stressor Peer Support registered a low risk. Employers should encourage staff to interact with each other and provide a support network of colleagues.

\section{Third-level Factors}

This section focuses on items relevant to the institutes of technology sector and seeks to gain a baseline information relating to work-related stress levels associated with each item. The fourteen items include: teaching, research, administration, teaching hours, flexi hours, ICT infrastructure, policies, consultation, decisions, career and pay. Respondents are requested to indicate their opinions on a five point Likert scale as to the risk levels from Very Low to Very High. The data in Figure 19 shows the percentage scores for the total sample group for the fourteen items.

Respondents reported the 'Flex hours' ${ }^{5}$ as the highest stress factor at 38\%, Very High risk and $23 \%$ High risk, with only $10 \%$ indicating Very low risk. The flexi hours as a productivity measure have increased the weekly teaching norm making the teaching workload excessive. This seems to be putting a significant percentage of academic staff at risk of experiencing work-related stress. Workload in terms of Timetabled teaching hours was identified as a strong work-related stress factor at 30\%, Very high $27 \%$, High and $24 \%$ Moderate. The current teaching timetable norm of 16 hours (Lecturer) and 18 hours (Assistant lecturer) per week is a remnant of a past decade and does not take into account the new realities of the contemporary academic work environment with the multiple competing demands on academics' time. The teaching timetabled hours per week needs to be reviewed to establish a norm appropriate to contemporary higher education practice.

The second highest work-related stress factor was 'Consultation on change' at 37\% Very High, 24\% High and 20\% Moderate risk. From the results it would seem that respondents consider their institute's approach to consultation on change is not adequate. The unnecessary uncertainty caused by lack of consultation results in high levels of risk of experiencing work-related stress. Associated factors also indicated elevated levels of risk

\footnotetext{
${ }^{5}$ The flex hours refers to two additional teaching hours per week, provided free by academics as productivity measure in the national agreements Public Service Agreement 2010-2014, Haddington Road Agreement 2014-2016.
} 
of work-related stress: Institute policy $26 \%$ Very high, $27 \%$ High and $25 \%$ Moderate and Contribution to decisions 31\% Very High, 23\% High and 21\% Moderate. It would seem that respondents have concerns with policies developed and implemented by their institute. Respondents also, seem to be concerned by their institutes' decision-making processes and its failure to provide opportunities for them to contribute to decision making.

Indication of stress levels associated with 3rd level Factors

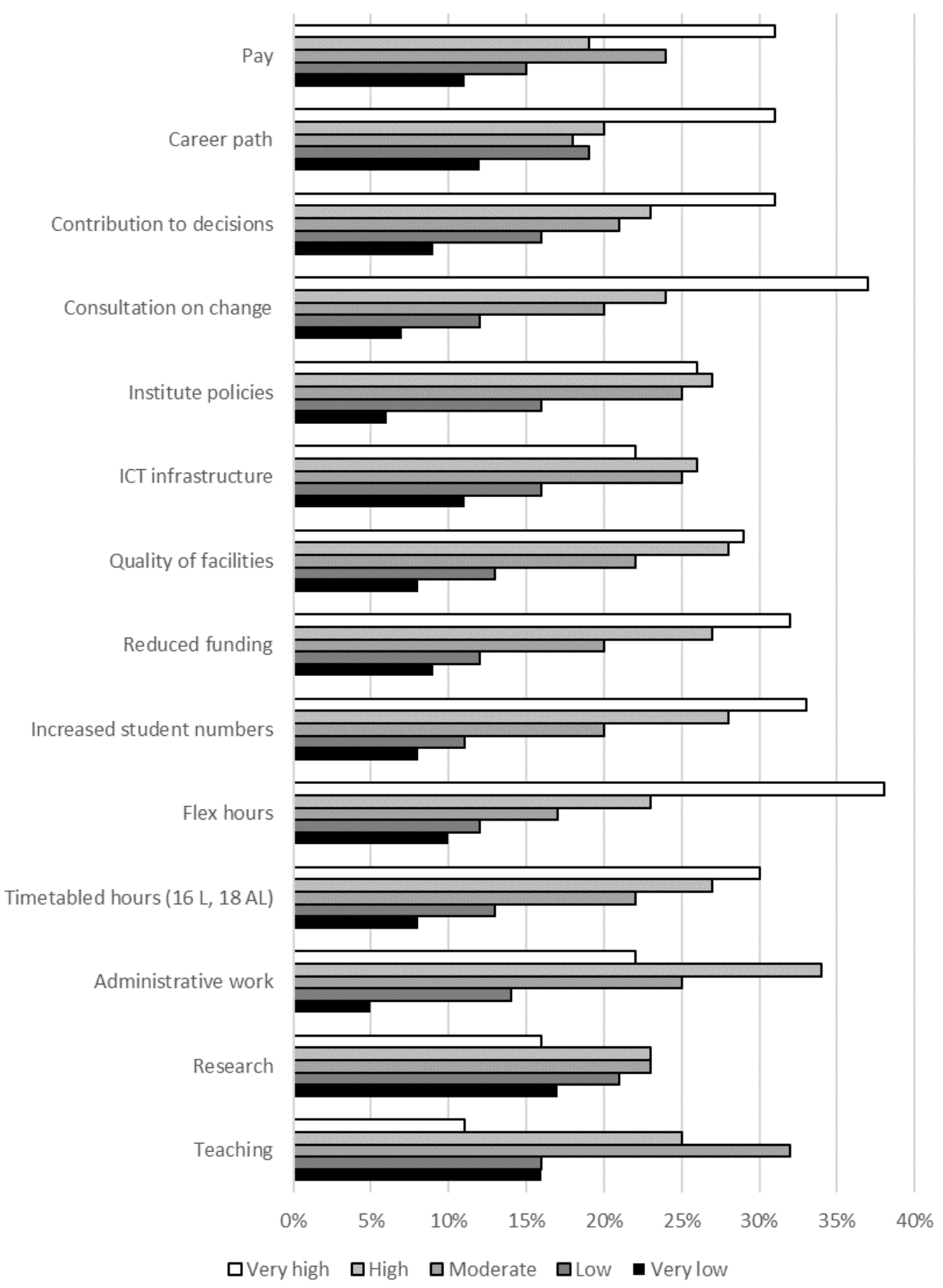

Figure 19 Responses in percentages for stress levels relating to 3rd level Factors 
Elevated work-related stress risk levels are associated with both 'Increased student numbers' 33\% Very High, 28\% High 20\% Moderate risk and 'Reduced funding' at 32\% Very High, $27 \%$ High and 20\% Moderate risk. Student number have increased by over $17 \%$ this is having a direct impact on increase workloads in teaching, feedback, assessment, administrative and pastoral care. This is further compounded by the impact that reduced funding $(-20 \%)$ is having on programme resources, equipment upgrading and maintenance. In some cases due to the increased class sizes students cannot get access to the labs or equipment needed to carry out their course work. These factors have obviously caused members to experience high levels of work-related stress.

Strong levels of risk of work-related stress are associated with the following factors: Pay $31 \%$ Very High, 19\% High and 24\% Moderate risk, Career path 31\% Very high, 20\% High and $18 \%$ Moderate. Similar levels of work-related stress are associated with factor Quality of facilities with $29 \%$ Very High risk, $28 \%$ high risk and 24\% Moderate risk. Respondents indicated the factor ICT infrastructure was causing work-related stress at $22 \%$ Very high risk, 26\% High risk and 25\% Moderate risk. Reductions in pay are obviously a cause of work-related stress. The responsibility however for the cuts must be directed at the government and not individual institutes. Institutes can assist staff to gain a living wage by reducing casualisation, by have policies that assist part-time, fixed-term and in some case CID holders to gain full hours. The development of fair, transparent and appropriate career pathway policies could assist in the process of reducing casualisation and opening up of progression opportunities. Concern was expressed by respondents relating to the quality of facilities and the ICT infrastructure. It would seem that cutbacks are resulting in reduced quality and this is affecting work-related stress levels. To alleviate this the HEA would have to provide the institutes with sufficient funding to update facilities and ICT equipment.

The three items most associated with academic work - teaching, research and administrative duties - registered more relative risk levels in comparison to the other 11 factors. For Teaching the risk levels were 10\% Very high, 25\% High and 32\% Moderate. In terms of Research the levels were 16\% Very high, 23\% High and 23\% Moderate, whilst Administrative work was 22\% Very high, 34\% High and 25\% Moderate. Over a third of respondents associated teaching and research with high levels of risk of experiencing workrelated stress, whereas over fifty percent indicated administrative duties as a high level risk factor. It would seem that the increase in administrative duties is considered more of a risk 
factor then teaching and research. In terms of the academic work process however, these three factors have a complex and inter-related relationship: increased demand on time in one factor leaves less time allocation to the others. The increased demand on administrative duties deviates from the substantive roles of teaching and research. This can result in increased work pressure and anxiety levels as academics endeavour to reconcile the competing demands of teaching and research duties by working more hours above what could be considered as reasonable and normal. In order to circumvent this dilemma and reduce the risk factor of experiencing work-related stress, clear time allocation guidelines and protocols need to be agreed. This would reasonably include the pro-rata reduction in the teaching timetable norm in order to allocate more time to other duties.

\section{Conclusion}

This is the first work-related stress survey carried out with academic staff working in the institute of technology sector. The survey findings present a unique baseline data set for future comparative purposes. The respondents indicated high levels of risk of work-related stress with Stressors: Change, Demand and Managers' support. Moderate to low levels of risk are indicated for Stressors: Role, Relationships and Peer support. Within the third-level sector workload factors were identified as the highest risk factors including Flexi hours, timetabled hours and increased student numbers. Other factors indicated with high risk of work-related stress were Consultation, Decision making, Pay and Career path.

From the data it is clear that a large percentage of academic staff consider they are experiencing very high to high levels of risk of work-related stress whilst carrying out their academic work. This requires interventions measures with a view to reduce the levels of work-related stress and the risk factors. It is an obligation of the employer to put in place appropriate and reasonable measures to reduce work-related stress. This type of survey run on an annual basis will provide a measure on the effectiveness of employers' reduction strategies.

Work-related stress is a serious workplace issue which has the potential to cause or contribute to physical illness, psychological illness and which can lead to the onset of, or increase in, harmful behaviours. To reduce work-related stress employers need to provide staff with sufficient information on work-stress, hold awareness events, establish 
workplace working groups to identify risk factors and put in place proactive measures to uncover work-related stress and develop intervention strategies to reduce it.

It is recommended that academic staff should:

- Inform themselves about the causes of work-related stress.

- Be aware of the potential risk factors associated with work-related stress.

- Note the potential adverse effect work-related stress can have on workers' health and well-being.

- If concerned about work-related stress discuss the matter with a colleague.

- If suffering from work-related stress notify the employer.

- If a Union representation or advice on a work-related stress grievance is required, contact either your workplace representative or a workplace officer.

It is recommended that employers

- Should work in partnership with trade unions to review existing work-related stress policies.

- Should establish and resource a working group consisting of union and management representatives to identify risk and preventative measures.

- Should have fit-for-purpose policies in place relating to work-related stress and how to take measures to prevent it. These policies should be reviewed on a regular basis.

- Should inform all staff of the work-related stress policies, providing information and advice on the support services which are provided.

- Should carry out regular risk assessments of work-related stress within the workplace.

- $\quad$ Should provide prompt assistance to staff suffering from work-related stress, putting measures in place to prevent the work-related stress and reduce risks.

- Should have protocols for the immediate intervention at the appropriate level to resolve cases of reported work-related stress.

This research has provided evidence of the levels of work-related stress experienced by academics working in the institute of technology sector in Ireland. The baseline data indicates the Stressors and Factors which require attention, and the onus on employers to develop appropriate intervention strategies with a view to reducing the risks of experiencing work-related stress. An annual work-related stress survey should be administered in order to measure the effectiveness of employers' interventions. Reducing levels of work-related stress will require the proactive engagement of all parties to create a cultural shift to more supportive work processes, practices and organisation. 


\section{References}

Blaikie N. (2007) Approaches to Social Enquiry, Polity, UK.

Byrne R. (2013) Safety and Health Acts: Annotated and Consolidated, Round Hall, Thomson Reuters, Ireland.

Hart C. (2005) Doing a Literature Review: Releasing the Social Science Research Imagination, Sage Publications, London, Thousand Oaks, New Delhi.

Health and Safety Authority (2010) Work-related Stress a Guide for Employers, URL link http://www.hsa.ie/eng/Publications and Forms/Publications/Occupational Health/Work Related Stress A Guide for Employers.pdf.

Health and Safety Authority (2011) Work-related Stress Information Sheet for Employees, http://www.hsa.ie/eng/Publications and Forms/Publications/Occupational Health/Work Related Stress In formation Sheet.pdf.

Health and Safety Authority (2014) Workplace Stress, URL link http://www.hsa.ie/eng/Workplace Health/Workplace Stress/Overview/Workplace Stress FAQs.html\#indica tors.

Health and Safety Executive (2014) Management Standards Work-related stress. URL link http://www.hse.gov.uk/stress/standards/index.htm .

Health and Safety Executive (2014) Work-related stress, URL link http://www.hse.gov.uk/stress/furtheradvice/wrs.htm .

Health and Safety Executive (2015) Stress-related and Psychological Disorders in Great Britain 2014, URL link, http://www.hse.gov.uk/statistics/causdis/stress/stress.pdf .

Herr R., McHugh M., McCrory M. (2009) Management Standards and stress-related work outcomes, Occupational Medicine Vol. 59, pp574-579, URL link http://www.hse.gov.uk/stress/managementstandards.pdf.

Horibe F. (1999) Managing Knowledge Workers, John Wiley \& Sons, Toronto, New York, Brisbane, Singapore.

International Labour Organisation (2012) International Standard Classification of Occupations, ILO Geneva.

Kerehner C., Koppich J., Weeres J. (1997) United Mind Workers; Unions and teaching in the knowledge society, Jossey-Bass, San Francisco.

MacHay C., Cousins R., Kelly P., Lee S., McCaig (2004) 'Management Standards' and work-related stress in the UK: Work and Stress, Vol. 18, No. 2, pp91-/112.

Nulty D. (2008) The adequacy of response rates to online and paper surveys: what can be done? Assessment \& Evaluation in Higher Education Vol. 33, No. 3, pp 301-314.

Robson C. (1993) Real World Research: a resource for Social Scientists and Practitioner- Researchers, Blackwell, UK and USA.

World Health Organisation (2004) Work Organisation and Stress, Protecting Workers Health, Series 3, URL Link file:///D:/WRS\%20survey/Work\%20organisation\%20and\%20stress\%20(1).pdf

World Health Organisation (2015) What is Work-related Stress? URL

http://www.who.int/occupational health/topics/stressatwp/en/accessed 21/1/2015. 